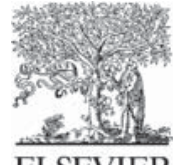

Available online at www.sciencedirect.com

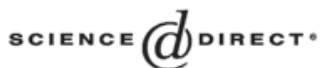

TH: rcotomice

\title{
The lasting impact of childhood health and circumstance
}

\author{
Anne Case*, Angela Fertig ${ }^{1}$, Christina Paxson ${ }^{2}$ \\ Center for Health and Wellbeing, Wallace Hall, Princeton University, Princeton, NJ 08544, USA \\ Received 4 May 2004; accepted 20 September 2004 \\ Available online 5 January 2005
}

\begin{abstract}
We quantify the lasting effects of childhood health and economic circumstances on adult health, employment and socioeconomic status, using data from a birth cohort that has been followed from birth into middle age. Controlling for parental income, education and social class, children who experience poor health have significantly lower educational attainment, poorer health, and lower social status as adults. Childhood health and circumstance appear to operate both through their impact on initial adult health and economic status, and through a continuing direct effect of prenatal and childhood health in middle age. Overall, our findings suggest more attention be paid to health as a potential mechanism through which intergenerational transmission of economic status takes place: cohort members born into poorer families experienced poorer childhood health, lower investments in human capital and poorer health in early adulthood, all of which are associated with lower earnings in middle age - the years in which they themselves become parents.

(C) 2004 Elsevier B.V. All rights reserved.
\end{abstract}

JEL classification: $\mathrm{I} 1 ; \mathrm{D} 1 ; \mathrm{J} 0$

Keywords: NCDS; Panel data; Life course models; Childhood health

\footnotetext{
* Corresponding author. Present address: 367 Wallace Hall, Princeton University, Princeton, NJ 08544-1013, USA. Tel.: +1 609258 2177; fax: +1 6092585974 .

E-mail addresses: accase@princeton.edu (A. Case), afertig@indiana.edu (A. Fertig), cpaxson@princeton.edu (C. Paxson).

1 Present address: Wylie Hall, Room 105, Indiana University, Bloomington, IN 47405, USA.

2 Present address: 316 Wallace Hall, Princeton University, Princeton, NJ 08544, USA.

0167-6296/\$ - see front matter (C) 2004 Elsevier B.V. All rights reserved. doi:10.1016/j.jhealeco.2004.09.008
} 


\section{Introduction}

Recent research has documented that children born into poorer families fall into poorer health as they age. These children arrive at the doorstep of adulthood not only in poorer health but also with lower educational attainment, in part attributable to their poorer health. (Case et al., 2002 provide evidence for the US, and Currie and Stabile, 2004 for Canada.) This research suggests that childhood health may be an important contributor to the "gradient", the widely documented positive association between good health and higher economic status observed in adulthood (Adler et al., 1994).

Research on determinants of adult health has varied in the weight it has placed on childhood health and circumstances. A strand of recent work suggests that nutrition in utero can affect health status in middle age, through its impact on such important chronic conditions as coronary heart disease and diabetes (Barker, 1995; Ravelli et al., 1998). New experimental work finds that mice whose fetal growth is restricted, but who are fed well after birth, exhibit rapid catch-up growth but die significantly earlier than mice well fed in utero (Ozanne and Hales, 2004). Children born to poor parents may be more likely to have had a poor fetal environment, leading to poor health in middle age. Having been raised in poorer families, such children are also more likely to earn less when they reach adulthood, leading to a correlation between earnings and health. In this way, the fetal-origins hypothesis could explain the positive association found between adult health and economic circumstance.

In a similar vein, some life course models emphasize the extent to which illness and deprivation in childhood have lasting effects on adult health — directly, through the illness itself, and indirectly, by restricting educational attainment and life chances (Kuh and Wadsworth, 1993). Life course models may also help to explain contemporaneous correlation between social status and health: those who have suffered chronic health conditions in childhood may reach adulthood in poorer health, and with less education and poorer labor market skills. Persistence in the processes generating earnings and health could lead to a contemporaneous correlation in earnings and health in adulthood that was due to conditions in childhood. Economists have contributed to this literature, examining the role played by health in education and labor market outcomes (see Currie and Madrian, 1999, for a review of the economics literature linking health to labor market outcomes, and Currie and Hyson, 1999, for an examination of the impact of low birthweight on educational attainment and labor market outcomes).

In contrast to these approaches, research centered on the role of adult socioeconomic status in determining adult health has largely argued that the observed correlation between income and health in adulthood is not directly attributable to childhood events. For example, Marmot et al. (2001) discuss their finding of a gradient in health among the subset of British civil servants whose parents survived to age 70 . They conclude that, in their data, "early-life circumstances are important because they influence adult social circumstances, which in turn influence disease risk" (p. 305). Such pathways models posit a causal link from low socioeconomic status earlier in adulthood to poor health later in adulthood, with childhood circumstances important because they affect initial adult socioeconomic position.

In this paper, we quantify the lasting effects of childhood health and economic circumstances on adult health, employment and socioeconomic status, using data from a birth cohort that has been followed from birth into middle age. Making progress in this area is 
difficult for several reasons. Few datasets track individuals from childhood into adulthood. Much of what is known about the dynamics of income and health status for the US comes from a survey of the elderly, which restricts analysis to changes in income, wealth, and health status at the end of life, and over a short period of time. ${ }^{3}$ Panel data exist for the UK for three birth cohorts - the 1946 National Survey of Health and Development (NSHD), the $1958 \mathrm{Na}-$ tional Child Development Study (NCDS, Centre for Longitudinal Studies, Bedford Group for Lifecourse and Statistical Studies, Institute of Education, http://www.cls.ioe.ac.uk/), and the 1970 British Cohort Study - and for two panels of British civil servants (the Whitehall I and II studies). However, these offer a more limited entry into the question than may first appear to be the case. Data from the 1946 cohort study are not publicly available, which restricts the extent to which any consensus could be reached using these data. The 1970 cohort is too young yet to trace childhood events very far into middle age. The Whitehall studies, which collected information on health and mortality of cohorts of British civil servants over time during working adulthood, contain only minimal retrospective information on family background. Results presented below suggest that, in particular, the lack of information on mother's education and own-health status in childhood limits the usefulness of the Whitehall data for quantifying the extent to which childhood circumstances can explain the relationship between health and economic status in adulthood. ${ }^{4}$ At the present time, the 1958 NCDS cohort provides the best opportunity to follow children across the bridge from childhood to adulthood.

There are difficulties in identifying causal relationships between health and socioeconomic status, even with the sort of rich, detailed data available for the NCDS. Unobserved factors, such as early-life experiences or genetic endowments, may drive both health and economic status over time. Experiments in which factors that affect economic status or health in early life are randomly altered may settle issues of causality, but the long-run impact of early-life nutrition and health interventions in some of the cleverly devised experiments being run today (Thomas et al., 2003; Gertler and Boyce, 2001) will not be fully realized for another 40 or 50 years.

Given the difficulties of drawing causal inferences, we proceed in two steps. Using data from the NCDS, we first present reduced form models that lay out the facts on the associations between childhood health and circumstance, on one hand, and educational attainment, adult health and socioeconomic status on the other. We then present more speculative estimates of the pathways through which prenatal and childhood health affect adult health and circumstance, making plain the assumptions necessary to attribute causal effects to different pathways.

We find, controlling for parental income, education and social class, that children who have experienced poorer uterine environments and poorer health in childhood have significantly lower educational attainment, poorer health and lower socioeconomic status as adults. Moreover, prenatal and childhood health appear to have direct effects on health and

\footnotetext{
${ }^{3}$ Adams et al. (2003), for example, use three waves of data from the Asset and Health Dynamics of the Oldest Old (AHEAD) data, collected between 1993 and 1998.

${ }^{4}$ Whitehall I contained "no direct data on the social circumstances of these men as children" (Marmot et al., 1984, p. 1004). Whitehall II collected information on father's occupation (retrospectively reported by the civil servants), on father's school leaving age, and on whether the civil servants' parents died before reaching age 70 .
} 
economic status in middle age: controlling for educational attainment, and for socioeconomic status and health in earlier adulthood, we find prenatal and childhood health markers are significant predictors of health and economic status at age 42 .

Overall, our findings suggest more attention be paid to health as a potential mechanism through which intergenerational transmission of economic status takes place: cohort members born into poorer families experienced poorer childhood health, lower investments in human capital and poorer health in adulthood, all of which are associated with a lower probability of employment and lower earnings in middle age - the years in which they themselves become parents.

\section{The 1958 National Child Development Study}

The NCDS has followed all children born in Great Britain (Scotland, England and Wales) in the week of March 3, 1958 from birth through to age 42. Parents were interviewed at the time of the birth, and medical, social, demographic and economic data have been collected on these children during follow-up interviews conducted at ages 7, 11, 16, 23, 33 and $42 .{ }^{5}$ Data from the study are available through the Centre for Longitudinal Studies (http://www.cls.ioe.ac.uk/).

Summary statistics for key variables are presented in columns 2 and 3 of Table 1. Our measures of prenatal and childhood health consist of an indicator that the child was of low weight at birth (less than $2500 \mathrm{~g}$ ); indicators of how much the child's mother smoked during pregnancy; the number of physician-assessed chronic health conditions observed at ages 7 and 16; and height at age 16. A third of all mothers reported that they smoked during their pregnancy, with $12 \%$ reporting that they smoked heavily. In our analyses, we include indicators for moderate, heavy and variable smoking while pregnant.

Chronic health conditions at ages 7 and 16 reflect both health problems the child was born with, and health problems acquired in childhood. Table 1 indicates that the average number of chronic childhood conditions is small. Of children who received medical exams at these ages, $6.2 \%$ of children had at least one chronic condition at age 7 , and $10.0 \%$ at age 16. In some analyses, we break chronic conditions into three categories: physical impairments (neck and head, spinal, upper and lower limb impairments, general motor handicaps, general physical impairments); mental and emotional conditions; and other 'systems' conditions (respiratory, alimentary, heart, haematological, urogenital, central nervous system, epilepsy). ${ }^{6}$ Height is included as a reflection of childhood (and possibly prenatal) nutrition. Because height also has a genetic component, we control for both mother's and father's heights in all models.

\footnotetext{
5 There has been attrition from the original sample of 17,409 children, and some families who miss a survey round are picked up in later surveys. Attrition does not appear to be systematically associated with socioeconomic status. (A detailed discussion is provided in the appendix to our working paper, available at http://www.wws.princeton.edu/chw/research/papers.php.) The survey has also added approximately 700 children born during the week of March 3, 1958 who immigrated to Great Britain prior to the age 16 survey. These children do not appear to be substantially different from the original sample, and we include these children in our analysis.

${ }^{6}$ These conditions are too rare in the NCDS cohort to analyze their impacts separately for each chronic illness.
} 
Table 1

Summary statistics, 1958 British Cohort Survey

\begin{tabular}{|c|c|c|c|c|}
\hline \multirow[t]{2}{*}{$\begin{array}{l}\text { Household and individual-level } \\
\text { variables }\end{array}$} & \multicolumn{2}{|c|}{ Full sample, men and women } & \multicolumn{2}{|c|}{$\begin{array}{l}\text { Sample of men used in } \\
\text { Tables } 5 \text { and } 6\end{array}$} \\
\hline & Mean (S.D.) & $\begin{array}{l}\text { No. of } \\
\text { observations }\end{array}$ & Mean (S.D.) & $\begin{array}{l}\text { No. of } \\
\text { observations }\end{array}$ \\
\hline \multicolumn{5}{|l|}{ Prenatal and childhood health } \\
\hline $\begin{array}{l}\text { Indicator: born at low } \\
\text { birthweight }\end{array}$ & $0.073(0.261)$ & 17409 & $0.043(0.203)$ & 5315 \\
\hline $\begin{array}{l}\text { Mother smoked heavily during } \\
\text { pregnancy }\end{array}$ & $0.123(0.328)$ & 17184 & $0.115(0.319)$ & 5242 \\
\hline $\begin{array}{l}\text { Number chronic conditions, age } \\
7\end{array}$ & $0.087(0.422)$ & 14321 & $0.083(0.355)$ & 4800 \\
\hline $\begin{array}{l}\text { Number chronic conditions, age } \\
16\end{array}$ & $0.141(0.539)$ & 11670 & $0.125(0.475)$ & 4161 \\
\hline Physical impairments, age 16 & $0.037(0.283)$ & 11670 & $0.034(0.255)$ & 4161 \\
\hline $\begin{array}{l}\text { Mental/emotional problems, } \\
\text { age } 16\end{array}$ & $0.037(0.216)$ & 11670 & $0.027(0.176)$ & 4161 \\
\hline Systems conditions, age 16 & $0.066(0.278)$ & 11670 & $0.064(0.271)$ & 4161 \\
\hline Height in meters, age 16 (all) & $1.66(0.085)$ & 11123 & & \\
\hline Height in meters, age 16 (men) & $1.70(0.08)$ & 5742 & $1.70(0.08)$ & 4008 \\
\hline \multicolumn{5}{|l|}{ Childhood circumstances } \\
\hline $\begin{array}{l}\text { Mother's age at leaving school } \\
\text { (median) }\end{array}$ & $15-16$ & 11432 & $15-16$ & 4059 \\
\hline $\begin{array}{l}\text { Father's age at leaving school } \\
\text { (median) }\end{array}$ & $14-15$ & 11092 & $14-15$ & 3981 \\
\hline $\begin{array}{l}\ln (\text { weekly family income) at age } \\
16\end{array}$ & $5.46(0.23)$ & 9415 & $5.47(0.21)$ & 3371 \\
\hline \multicolumn{5}{|l|}{ Outcomes } \\
\hline $\begin{array}{l}\text { Number of any O-level passes at } \\
\text { age } 16\end{array}$ & $1.96(2.75)$ & 14325 & $2.06(2.80)$ & 4831 \\
\hline $\begin{array}{l}\text { Self-reported health status at } \\
\text { age } 23\end{array}$ & $1.66(0.67)$ & 12521 & $1.60(0.65)$ & 4660 \\
\hline $\begin{array}{l}\text { Self-reported health status at } \\
\text { age } 33\end{array}$ & $1.81(0.70)$ & 11267 & $1.77(0.69)$ & 4686 \\
\hline $\begin{array}{l}\text { Self-reported health status at } \\
\text { age } 42(1=\text { excellent, } \\
2=\text { good, } 3=\text { fair, } 4=\text { poor })\end{array}$ & $1.92(0.76)$ & 11371 & $1.91(0.76)$ & 5601 \\
\hline $\begin{array}{l}\text { Indicator: employed full-time or } \\
\text { part-time at time of survey, } \\
\text { age } 33\end{array}$ & & & 0.92 & 4720 \\
\hline $\begin{array}{l}\text { Indicator: employed full-time or } \\
\text { part-time at time of survey, } \\
\text { age } 42\end{array}$ & & & 0.90 & 5605 \\
\hline \multicolumn{5}{|l|}{ Socioeconomic status at age $42(\%)$} \\
\hline Professional & & & 7.1 & 5439 \\
\hline Managerial & & & 38.6 & 5439 \\
\hline Skilled manual & & & 9.5 & 5439 \\
\hline Non-skilled manual & & & 32.7 & 5439 \\
\hline Semi-skilled & & & 9.3 & 5439 \\
\hline Unskilled & & & 2.8 & 5439 \\
\hline
\end{tabular}

Notes: All money amounts are in $1987 £$. The "full sample" includes all individuals who appeared in the relevant year of the survey. The sample used in Tables 5 and 6 is of men with either non-missing data on health status or socioeconomic status at age 42 . Men with socioeconomic status coded as "other" at age 42 were not included in the sample used for Tables 5 and 6. 
Measures of family background include indicators for the ages at which the cohort member's mother and father left school; indicators for mother's marital status at the time of the cohort member's birth; the number of siblings in the cohort member's household at age 16; log family weekly income at age $16,{ }^{7}$ as well as father's social class at the time of the birth, and grandfathers' social classes at the time the cohort member's mother and father left school. ${ }^{8}$ Measures of social class are commonly collected in British surveys, and are based on occupation (professional, managerial, non-manual skilled, manual skilled, semi-skilled, and unskilled). The appendix to our working paper provides a complete list of these variables, and discusses our treatment of missing values. $^{9}$

Our primary health outcome measures are individuals' self-reported health status, measured at ages 23, 33 and 42. Each respondent was asked "How would you describe your health generally? Would you say it is . . . excellent, good, fair, or poor?" Self-reported health has been shown to predict mortality, even when controlling for physician assessed health status and health-related behaviors. (See Idler and Kasl, 1995, for an extensive set of references on studies of self-reported health and mortality.) In the NCDS, self-reported health status at ages 33 and 42 are highly correlated with reports that respondents have chronic conditions, and with reports of their disabilities and hospitalizations. Consistent with results from a wide variety of cross-sectional studies, members of the NCDS cohort report worse health at higher ages. The percentage of men reporting themselves to be in excellent health falls from $48 \%$ at age 23 , to $36 \%$ at age 33 , and to $31 \%$ at age 42 . Patterns are similar for women although, consistent with results from many other studies, women in the NCDS on average report worse health than men in middle age (see Case and Paxson, 2004, and references therein).

We examine the effects of childhood health and circumstance on education and two labor market outcomes in adulthood: employment and socioeconomic status. We choose to analyze socioeconomic status - instead of earnings - both to follow the literature in this area, and to avoid problems of censoring. Our primary measure of education is the number of O-level exam passes at age 16. As discussed below, similar results are obtained when alternative measures of education are used. Additional information on the British educational system and the construction of the measure of educational attainment is provided in the appendix to our working paper.

The employment measures we use are indicators for whether the respondent worked either part-time or full-time at ages 33 and 42 . Ninety percent of men are employed parttime or full-time at ages 33 and 42, and the vast majority of men work full-time (30 or more hours per week). Employment rates are lower for women, with less than $50 \%$ of women working full-time at either of these ages. Because a substantial fraction of women

\footnotetext{
${ }^{7}$ This variable was constructed using information on income categories for both parents together with information from the British Family Expenditure Survey from 1974. See the appendix of our working paper for details. All results presented here are robust to replacing our constructed family income measure with a set of 28 indicator variables for mother's and father's income categories at age 16, including indicators that parents' incomes were not recorded.

${ }^{8}$ We have experimented with including controls for parents' age at the time the child was born. Although these variables are at times jointly significant, their inclusion does not affect other results.

${ }^{9}$ This is available at http://www.wws.princeton.edu/chw/research/papers.php.
} 
Men

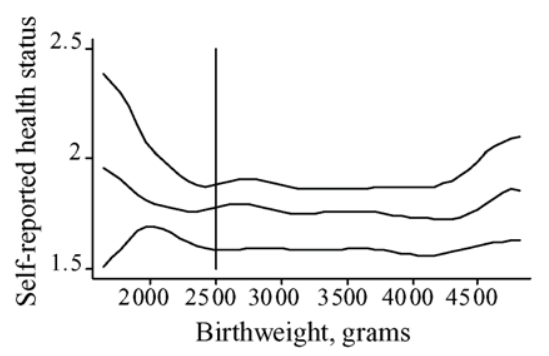

Women

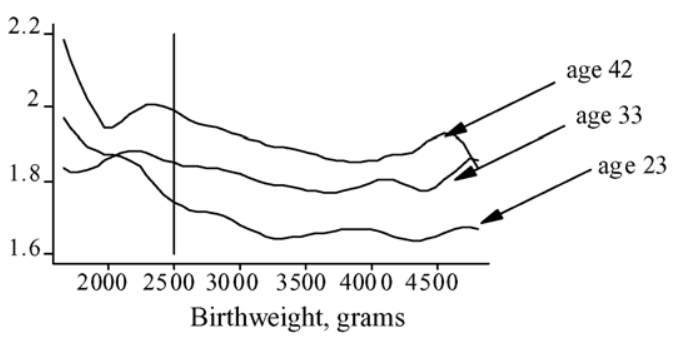

Fig. 1. Birthweight and health status in adulthood.

do not work, we restrict our analysis of employment and socioeconomic status (derived from occupation) to men only.

Fig. 1 presents preliminary information on the relationship between birthweight and health status in adulthood. The left panel shows locally-weighted regressions of health status at ages 23, 33 and 42 on birthweight for men in the NCDS who reported health status at all three ages. Men born at birthweights below $2500 \mathrm{~g}$ ( 88 ounces) report the worst health in middle age. This figure provides a rationale for using the cut-off value of $2500 \mathrm{~g}$ to denote low birthweight. The right panel shows similar regressions on health status in adulthood for women. In both panels, birthweight is observed to be related to health status in adulthood, with the relationship between low birthweight and health becoming more pronounced at older ages.

Section 3 presents reduced form estimates of the associations between childhood health and circumstances and adult outcomes, including education, adult health, employment and socioeconomic status. By themselves, the results we present in Section 3 do not provide information on the mechanisms that link health and economic outcomes over the life cycle. The issue of disentangling these links will be taken up in Section 4.

\section{Childhood health and outcomes in adulthood}

\subsection{Educational attainment}

Table 2 examines the relationship between childhood health and human capital investment. While the table focuses on the total number of O-level exams the child has passed by age 16, estimates of models for other educational outcomes - passing the English O-level, the Math O-level, and highest educational achievement-yield very similar results. In all cases, there is a significant association between health in childhood and educational attainment. On average, each childhood condition at age 7 is associated with a 0.3 reduction in the number of O-levels passed, and each condition at age 16 with an extra 0.2 reduction. That chronic conditions at age 7 have a larger association with educational attainment for all of our measures of human capital investment than do chronic conditions at age 16 is 


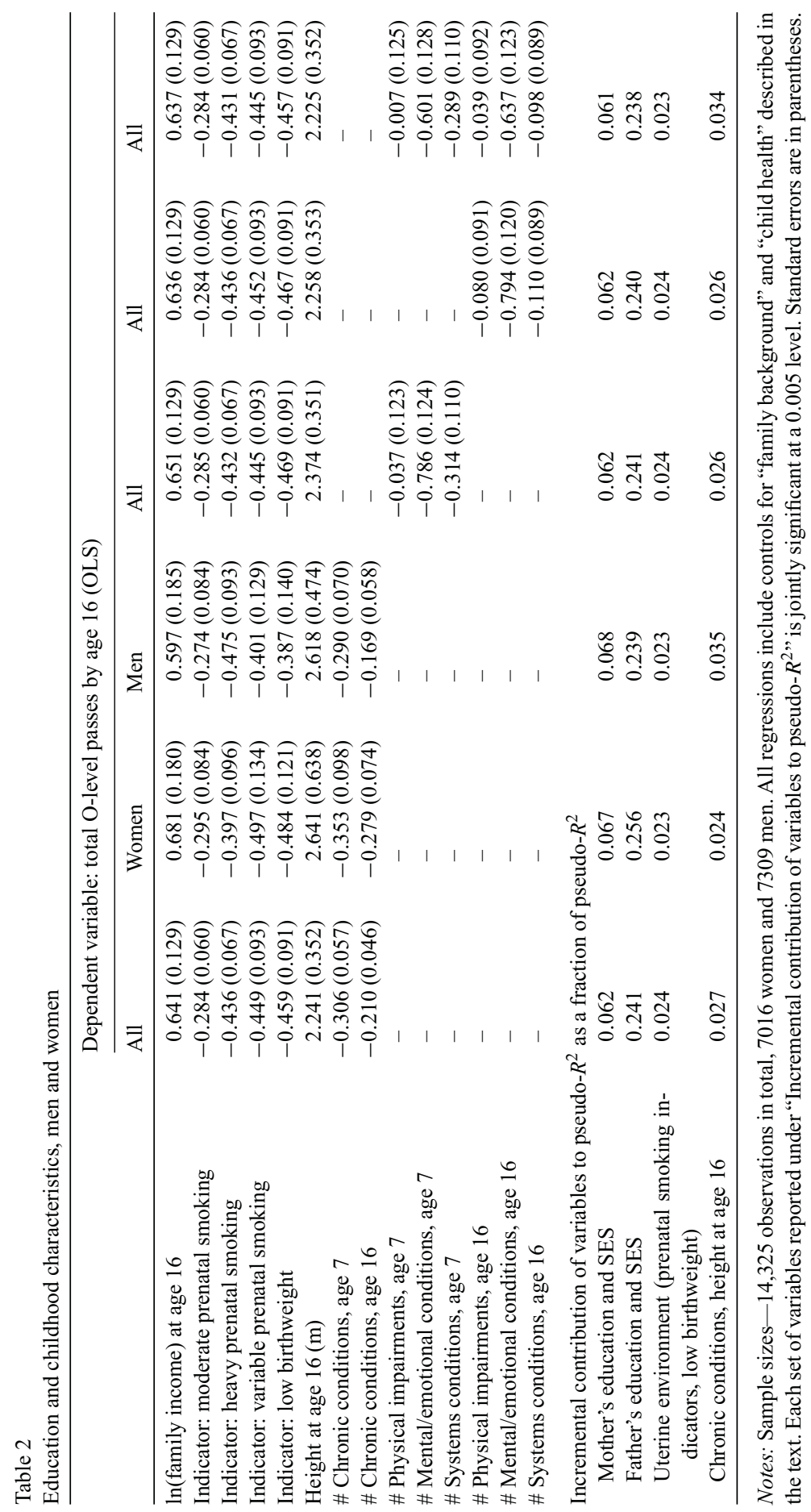


consistent with a model in which the harm inflicted by chronic conditions is cumulative in its effect on education. ${ }^{10}$

We also find strong associations between fetal conditions and children's educational attainment. Children born at low birthweight pass 0.5 fewer O-level exams on average. ${ }^{11}$ Moreover, mother's smoking during pregnancy is associated with significantly fewer Olevels passes, with children whose mothers reported having smoked heavily during pregnancy passing 0.4 fewer O-level exams. We tested whether these results varied, depending upon whether low birthweight was the result of a shorter gestational age, but found no significant differences between the outcomes for children who were born premature, and those who were low birthweight but were carried to term.

These results are consistent with theories that highlight the importance of the fetal environment, and the results for mother's smoking during pregnancy may represent the causal effect of smoking on fetal development and later cognitive development. Smoking during pregnancy has also been implicated as a source of behavioral and cognitive problems among older children, including lower IQ and attention deficit hyperactivity disorder (IOM, 2001), all of which could have adverse effects on educational attainment. Animal models support the hypothesis that prenatal nicotine exposure affects brain development and may have long-lasting effects (see, for example, Slotkin, 1998). Alternatively, the association between prenatal smoking and lower educational attainment we observe may be due to family and environmental characteristics associated with prenatal tobacco use. The dangers of smoking during pregnancy may not have been widely known in 1958, so the argument that it was less caring mothers who were more likely to smoke may not be as salient for this cohort. However, mother's smoking may be a marker for her social status that is not measured by family income, her education, or her father's social class, and the association between prenatal smoking and education could work through this channel.

Childhood socioeconomic circumstances are also correlated with educational attainment. Consistent with a large body of literature, we find that children from higher-income families have higher educational attainment. Even controlling for mother's and father's schooling and parents' and grandparents' social classes, a doubling of family income at age 16 is associated on average with passing 0.65 additional O-levels, and a 10 percentage point increase in the probability that the English and Math O-levels are passed. Parental schooling is also strongly associated with children's schooling. The coefficients for the indicators of mother's and father's school-leaving age, graphed in Fig. 2, indicate that later school-leaving ages (greater educational attainments) for both mothers and fathers are associated with a higher number of O-levels passed. Children whose mothers left school at ages 13-14 passed one fewer O-level exam on average than those whose mothers left at ages 17-18, and two fewer O-levels than those whose mothers stayed in school until ages 21-23.

\footnotetext{
10 These results are consistent with those presented in Gregg and Machin (1998) who use the NCDS data to study youth labor markets. They find having been sick in the past year with either minor or more serious ailments is negatively and significantly correlated with staying on in school at age 16.

${ }^{11}$ Currie and Hyson (1999) also find negative effects of low birthweight on O-level passage in the NCDS data. They also examine whether the effects of low birthweight differed by father's socioeconomic class at the time of the birth. We find, with our controls for family background and health, that such interactions are not significant, and we do not include them in our analysis.
} 


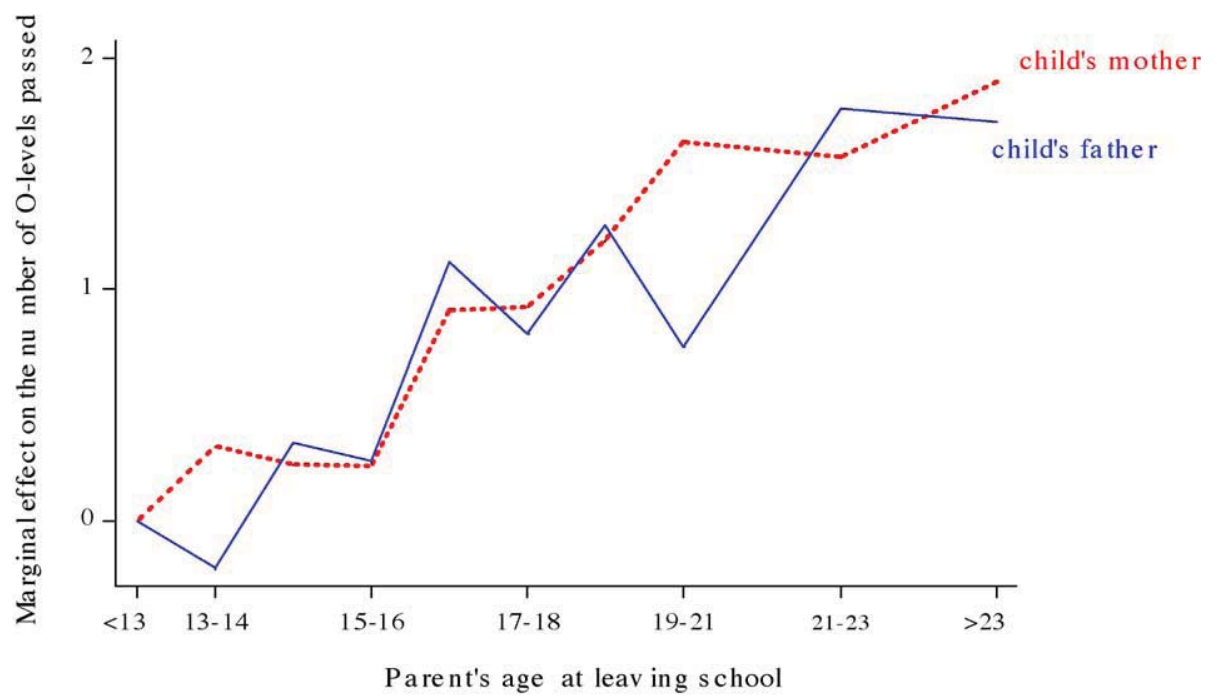

Fig. 2. Marginal effects of mothers' and fathers' education on the number of O-level exams passed.

To assess how much of the variance in educational attainment is explained by different sets of family background and childhood characteristics, we classified the control variables into four groups and calculated the incremental addition to the $R^{2}$ when each group of variables is added to a regression that includes all other variables. The groups of variables we examine include: (i) indicators for mother's education and social class (her school-leaving age, and her father's social class when she left school); (ii) father's education and social class (his school-leaving age, his father's status when he left school, and his social class at the time of the cohort member's birth); (iii) indicators of uterine environment (prenatal smoking, and an indicator for low birthweight); and (iv) variables registering childhood health (height at age 16, and the chronic conditions cohort members were observed to have suffered at ages 7 and 16). The measures of incremental $R^{2}$, expressed as a fraction of the total $R^{2}$ for the full regression, are shown in the bottom of Table 2. Of these groups of variables, those measuring father's education and social class provide the largest incremental contribution (approximately $25 \%$ ) to the explained sum of squares. This is chiefly driven by father's social status at the time of the respondent's birth, which alone contributes $12 \%$. Prenatal and childhood health variables each contribute roughly $2.5 \%$.

Columns 3 and 4 , which split the sample by gender, indicate that the associations between family and childhood characteristics and education are similar for men and women. The last columns of Table 2 take a closer look at the association between type of chronic condition and educational attainment. We find different types of childhood problems have different associations with education. There is no significant association between physical impairments, either at age 7 or 16, and educational attainment. In contrast, mental and emotional conditions are each associated with a significant reduction in O-levels passed. "Systems" conditions, which include lung, heart, digestive, blood, urogenital and neurological conditions, are also negatively and significantly correlated with O-levels passage if reported 
at age 7. Consistent with a model in which systems problems have a cumulative effect on education, an additional condition of this type is associated with 0.29 fewer O-levels if reported at age 7, and 0.10 fewer O-levels if first reported at age 16 .

\subsection{Adult health}

Table 3 documents the association between childhood characteristics and health status at ages 23, 33 and 42 . These results are from ordered probits of health status (integers from $1=$ excellent to $4=$ poor) run on our complete set of childhood controls. Children's fetal environments (mothers' prenatal smoking, and being born at low birthweight) are significantly associated with poor health in adulthood, with the correlation becoming larger and more significant as the birth cohort ages. The association between heavy prenatal smoking and health status is small and insignificant at age 23, with a marginal effect of heavy maternal prenatal smoking associated with a 0.034 increase (worsening) in reported health status on average. This association becomes larger and significant at age 33 (0.141), and larger still at age $42(0.163)$. The incremental contribution of the uterine environment to the explained sum of squares rises from 0.027 to 0.051 between ages 23 and 33, and rises to 0.086 at age 42 . This is consistent with models, such as the fetal origins hypothesis, that suggest fetal insult may trigger poor health outcomes in middle age. We examine alternative hypotheses below.

Chronic conditions in childhood show a different pattern. The coefficients on conditions at age 7 decline with age and become insignificantly associated with reported health status by age 42 , while coefficients on conditions at age 16 remain significant, and roughly constant, from age 23 to 42 . If a child had a chronic condition at age 7 that had disappeared by age 16 , our results suggest we should expect no significant association between that condition and health at age 42 . However, chronic conditions developed before age 7 that persist to age 16 , and those a child developed between ages 7 and 16, have a significant association with self-reported health throughout middle adulthood. The last two columns of Table 3 show results in which only one of our two measures of chronic conditions is used as a control in our health status ordered probits. Column 5 presents results using the number of conditions at age 7, and column 6 at age 16. The results in column 5 confirm that chronic conditions at age 7 are significantly correlated with health outcomes at age 42 . However, the lasting association with adult health is generated by the subset of these conditions that persists to age 16 .

Several measures of socioeconomic status in childhood are also related to adult health. Family income at age 16 becomes a larger and more significant predictor of health status with age in adulthood. At age 23, family income at 16 takes a coefficient of -0.069 and is not significantly different from zero. However, the effect increases in absolute value and significance with age, so that by age 33 it is -0.135 and by age 42 it is -0.143 .

Mothers' school-leaving age is also significantly associated with adult health. As was the case for family income, the association between mothers' education and health becomes more pronounced with age. This can be seen in Fig. 3, which graphs the coefficients on the indicators for maternal education in ordered probits for health status at ages 23, 33 and 42 . At age 23 , there is little correlation between mothers' school-leaving age and the cohort members' health. However, by age 33, maternal education has become strongly associated with 


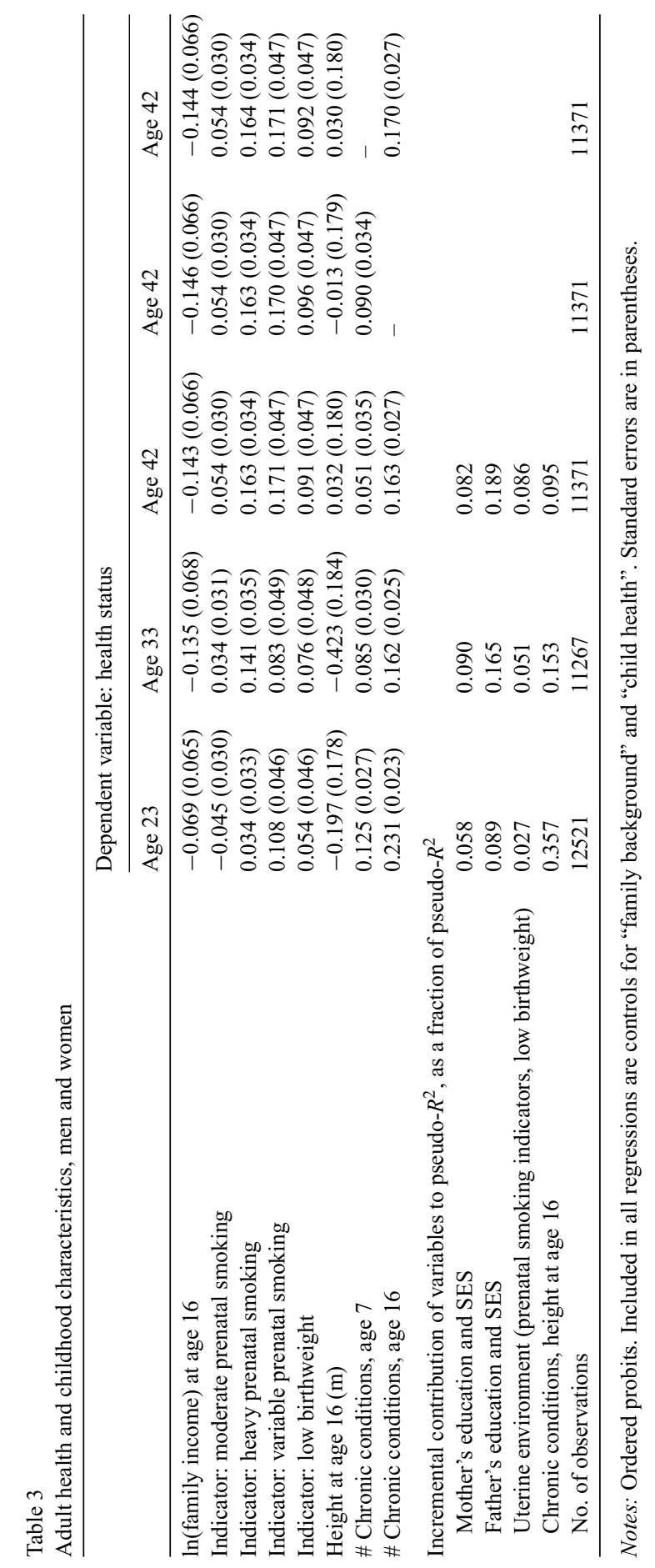




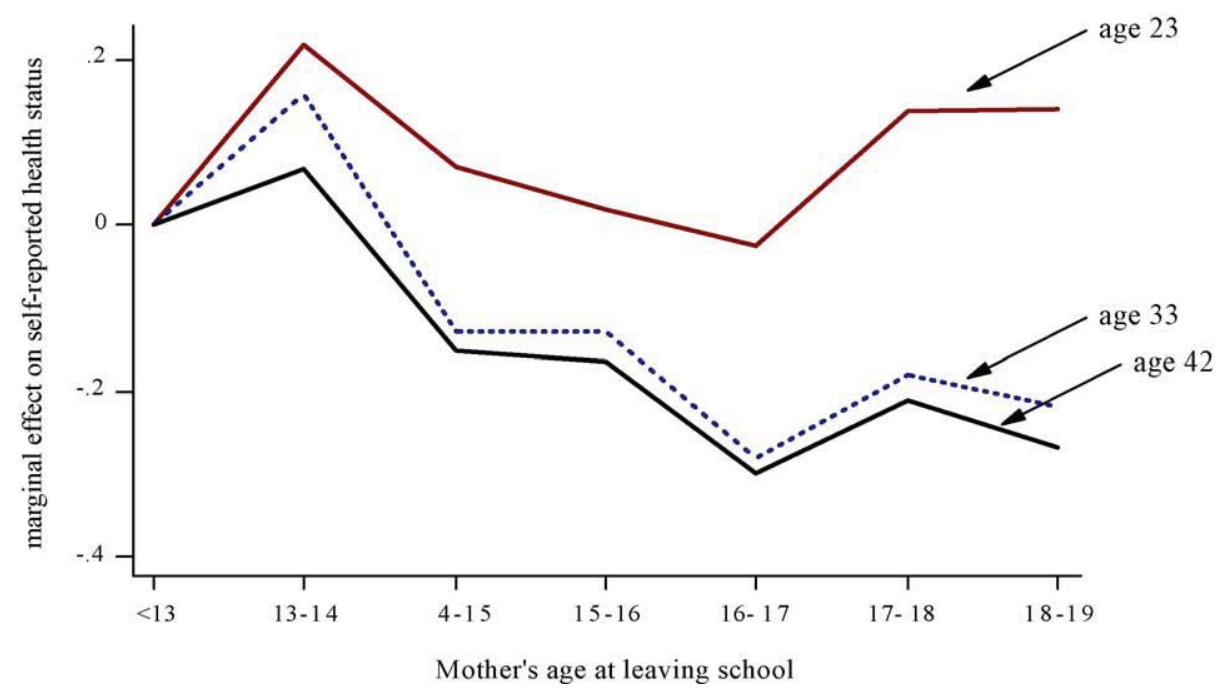

Fig. 3. Marginal effects of mothers' education on self-reported health status.

better health status. The chi-square test for the joint significance of indicators of mother's school-leaving age is large and significant (chi-square test $=22.04, p$-value $=0.0087$ ). In contrast, indicators for fathers' school-leaving ages are not jointly significant at either age 33 or 42 (for age 33, chi-square test $=10.02, p$-value $=0.3490$ ). Earlier research has documented the extent to which mothers act as gatekeepers for children's health. ${ }^{12}$ The results here are consistent with this gatekeeping having long-run benefits for their children.

More important than father's education is his social class at the time of the child's birth. Social class is strongly related to adult health, and contributes a larger share to the pseudo- $R^{2}$ at 33 than 23, and at 42 than at age 33 . These results translate into children with unskilled fathers being 8.3 percentage points more likely to be in fair or poor health at age 42 than the children of professionals. Collectively, father's education and social status represent an incremental contribution of nearly $20 \%$ to of the pseudo- $R^{2}$ of health at age 42 .

When no other controls are included, height at age 16 is significantly associated with better health at ages 23,33 and 42 , although the association becomes somewhat weaker with age. However, children's heights at age 16 are highly correlated with fathers' education and social economic status. When both height at age 16 and father's education and SES variables are jointly included as controls, the relationship between height at age 16 and health at age 42 is no longer significant.

We break these results down further in Table 4, where we examine the relationship between type of childhood chronic condition and adult health status, and the association

\footnotetext{
${ }^{12}$ Using data from the US National Health Interview Survey (NHIS), Case and Paxson (2001) show that for children ages $1-17$, mothers' education is a significant predictor of the child having had a routine doctor and dentist visit in the past 12 months, and with having a regular place for usual medical care and sick care. In the NHIS data, these authors find no significant correlation between father's education and routine doctors visits, or having a place for routine or sick care.
} 


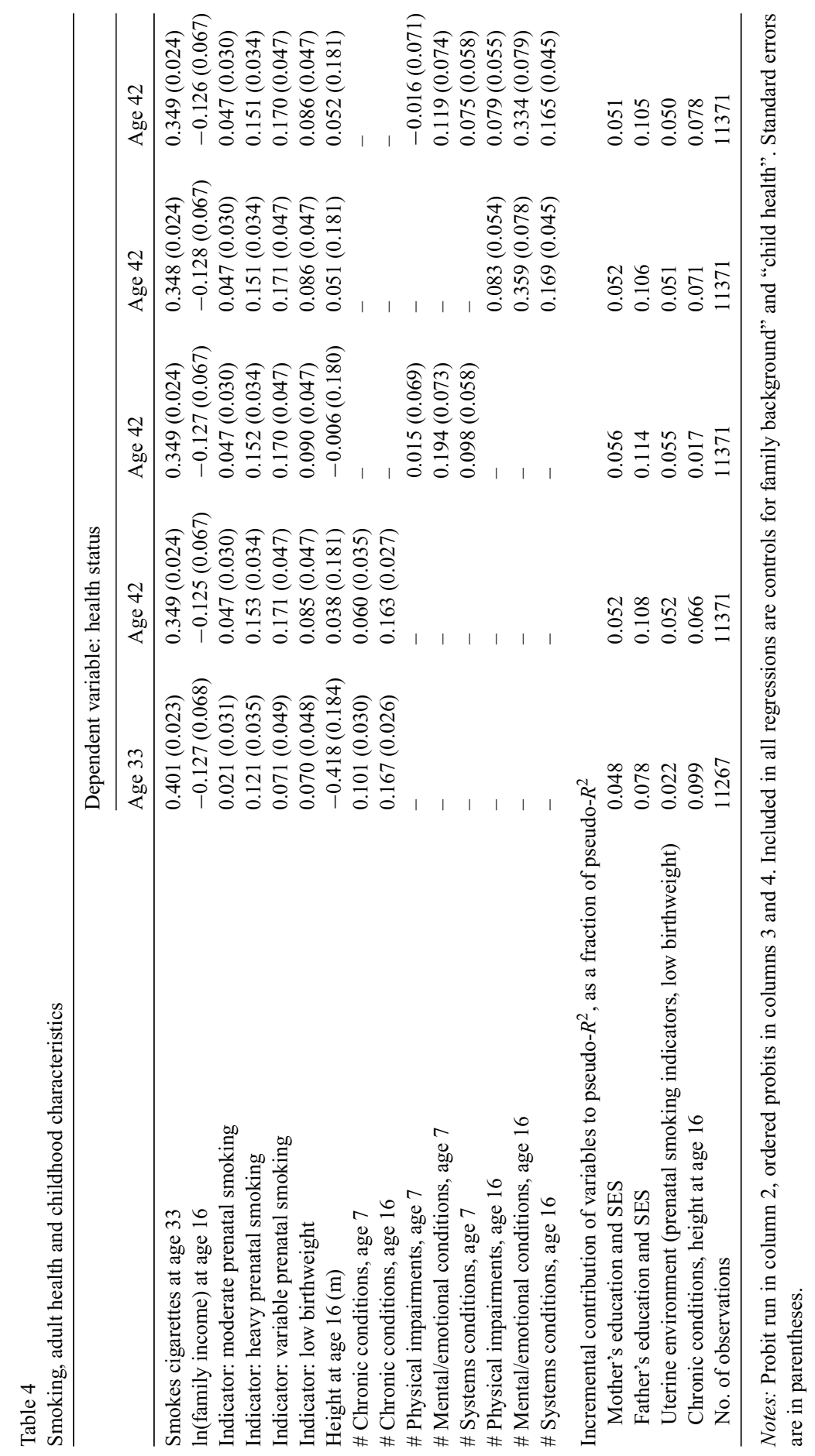


between a cohort member's own-smoking, mother's prenatal smoking, and health status in adulthood. That mothers' prenatal smoking is a significant predictor of own-health, and one that grows in importance with age, led us to examine whether part of this association works through the birth cohort member's own smoking behavior. It may be that respondents who grew up in environments in which mothers smoked heavily would be more likely themselves to smoke. (In results estimated, but not reported in Table 4, we find that children born to mothers who reported smoking heavily while pregnant were 5.9 percentage points more likely to report that they smoked at age 33.) Respondents' own smoking could lead in turn to reports of poorer health status.

To examine whether this accounts for the association we find between mother's smoking in pregnancy and own-reports of health in middle age, we control for smoking at age 33 in Table $4 .{ }^{13}$ We find that own-smoking is significantly correlated with reported health status, associated on average with a 0.40 increase (worsening) in own-health reports. However, inclusion of a smoking indicator does not change the strong association found between mothers' smoking while pregnant and respondents' own-health reports at age 33 and 42 . While this association may be due to a third factor, that third factor does not appear to be the respondent's own smoking.

Table 4 also examines whether different types of chronic conditions are differentially associated with reports of poorer health in adulthood. Physical impairments reported at age 7 show no significant association with health status in adulthood, with or without controls for physical impairments at age 16. While physical impairments reported at age 16 are only weakly associated with poorer health at age 42, mental and emotional conditions and systems conditions in childhood are large and significant correlates of poorer health in adulthood. As observed in Table 3, those conditions present at age 7 are significantly associated with poorer health in adulthood only if they continue to be present at age 16 .

\subsection{Employment and socioeconomic status in adulthood}

Table 5 presents estimates of the associations between childhood health and circumstances and employment and social status for men at ages 33 and 42 . We find chronic health conditions in childhood are significantly associated with employment in adulthood. An additional chronic condition at age 16 is associated with a 4 percentage point reduction in the probability of employment at age 33, and a 5 percentage point reduction in the probability of employment at age 42. As was true of adult health, chronic conditions at age 7 are associated with a lower probability of employment at age 42 only if these conditions continued to be present at age 16. Taken together, childhood health measures (conditions at ages 7 and 16 , and height at age 16) provide a large incremental contribution to the pseudo- $R^{2}(0.25)$ at ages 33 and 42 .

Childhood circumstances are also significantly associated with employment for men, with the education and social class of the cohort members' father significantly correlated with employment at ages 33 and 42 . Collectively, these variables also contribute almost 0.20 to the pseudo- $R^{2}$ at ages 33 and 42 . Men whose fathers were unskilled at the time of

\footnotetext{
${ }^{13}$ We code the variable "smokes at age 33" equal to one if the respondent reported smoking any cigarettes, and equal to zero otherwise. Using this definition, $33 \%$ of both men and women report smoking.
} 


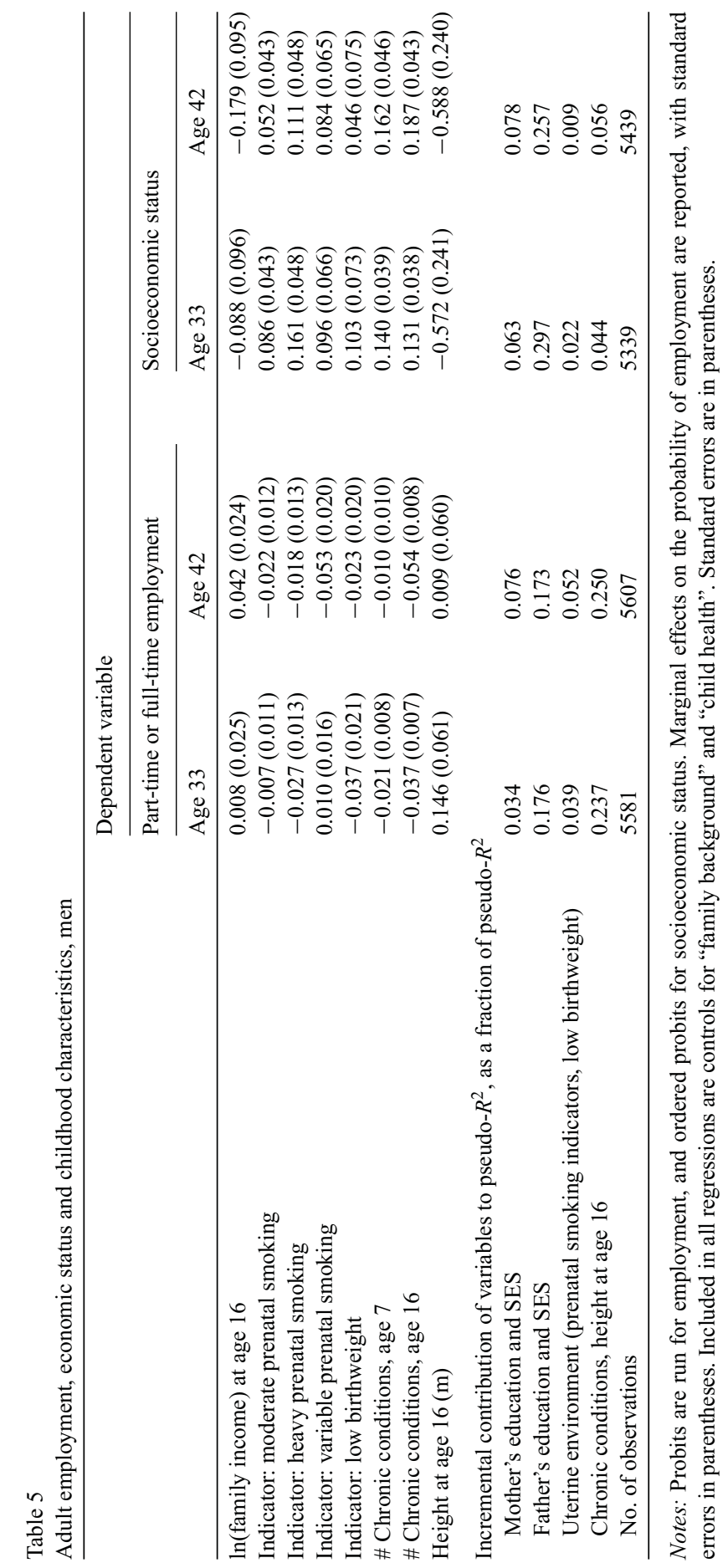


their births are 5 percentage points less likely to be employed at ages 33 and 42 than are men with professional fathers.

Table 5 also shows that health in childhood is significantly correlated with adult socioeconomic status. We run ordered probits of socioeconomic status $(1=$ professional, $6=$ unskilled labor), so that a higher reported coefficient is associated with a lower social status. Among 42-year-old men, an additional chronic condition at age 7 is associated with a 0.16 reduction in social status, and an additional condition at age 16 with a 0.19 reduction.

Consistent with findings in the intergenerational mobility literature (Reville, 1995), family income at age 16 becomes a larger and more significant correlate of men's social status as they age. The coefficient on family income at age 16 is -0.09 in ordered probits of social status at age 33 , and -0.18 for status at age 42 . Father's education and social class are also significantly correlated with status in middle age. Collectively, these variables contribute almost 0.26 to the pseudo- $R^{2}$ at age $42 .{ }^{14}$

\section{The dynamics of health and social status in adulthood}

\subsection{Empirical framework}

Our results in Section 3 show large, positive and significant associations of health in childhood with educational attainment, adult health, employment and social status. As we emphasized in Section 1, the interpretation of these findings requires caution: in the absence of experimental evidence, it is impossible to rule out that these associations are driven by unobserved "third factors" that influence both childhood health and adult circumstances. However, the fact that the associations between childhood health and adult outcomes are robust to the addition of controls for a large set of family background measures lends credibility to a causal interpretation. In this section, we assume that the associations we have documented do in fact reflect causal relationships. We then consider several alternative models of how childhood health affects the dynamic relationship between health and economic status in adulthood.

To illustrate ideas, we express socioeconomic status in middle age $\left(e_{\mathrm{M}}\right)$ and a measure of health in middle age $\left(h_{\mathrm{M}}\right)$ as linear functions of indicators of socioeconomic status and health in young adulthood ( $e_{\mathrm{Y}}$ and $h_{\mathrm{Y}}$, respectively), educational attainment at age $16(S)$ and a vector of prenatal and childhood characteristics $\boldsymbol{C}$, which includes measures of socioeconomic status in childhood, prenatal health, and health in childhood: ${ }^{15}$

$$
e_{\mathrm{M}}=\beta_{0}+h_{\mathrm{Y}} \beta_{\mathrm{h}}+e_{\mathrm{Y}} \beta_{\mathrm{e}}+\boldsymbol{C} \beta_{\mathrm{C}}+S \beta_{\mathrm{S}}+\varepsilon_{\mathrm{M}}^{\mathrm{e}},
$$

\footnotetext{
${ }^{14}$ Results are similar when we examine log earnings at ages 33 and 42 for men (not reported in Table 5). We find chronic conditions at ages 7 and 16, and height at age 16 are all significant predictors of earnings. In addition, the association between family income at age 16 and own-earnings becomes larger and more the significant as men age. Contributions to the $R^{2}$ of the family background, prenatal and childhood health variables are similar in size for SES and log earnings equations.

15 We characterize ages 23 and 33 as "younger adulthood", and age 42 as "middle adulthood".
} 


$$
h_{\mathrm{M}}=\alpha_{0}+h_{\mathrm{Y}} \alpha_{\mathrm{h}}+e_{\mathrm{Y}} \alpha_{\mathrm{e}}+\boldsymbol{C} \alpha_{\mathrm{C}}+S \alpha_{\mathrm{S}}+\varepsilon_{\mathrm{M}}^{\mathrm{h}} .
$$

Health and socioeconomic status in young adulthood are assumed to be functions of prenatal and childhood characteristics:

$$
\begin{aligned}
& e_{\mathrm{Y}}=\gamma_{0 \mathrm{e}}+\boldsymbol{C} \gamma_{\mathrm{e}}+v_{\mathrm{Y}}^{\mathrm{e}}, \\
& h_{\mathrm{Y}}=\gamma_{0 \mathrm{~h}}+\boldsymbol{C} \gamma_{\mathrm{h}}+v_{\mathrm{Y}}^{\mathrm{h}}, \\
& S=\gamma_{0 \mathrm{~s}}+\boldsymbol{C} \gamma_{\mathrm{s}}+v_{\mathrm{s}} .
\end{aligned}
$$

Substitution of (3)-(5) into (1) and (2) yields reduced form equations for health and socioeconomic status in middle adulthood, estimates of which were presented in the last section. Estimates of Eq. (5) are presented in Table 2.

Parameter estimates from (1) and (2) shed light on several issues. Estimates of $\beta_{\mathrm{C}}$ and $\alpha_{\mathrm{C}}$ provide information on whether childhood circumstances have direct effects on outcomes in middle adulthood even controlling for earlier adult outcomes, or whether the effects of childhood circumstances in middle adulthood work through their effects on outcomes in early adulthood. The former hypothesis is consistent with the fetal origins hypothesis, which predicts that prenatal development will affect health in middle age, independent of earlier health outcomes. If true, we would expect in Eq. (2) that, controlling for health in childhood and early adulthood, variables associated with prenatal development that are included in $\boldsymbol{C}$ will have significant effects on health in middle age. The literature on the fetal origins hypothesis stresses the importance of prenatal nutrition, in particular micronutrients, something not directly measured in the NCDS. However, indicators of low birthweight and maternal smoking during pregnancy provide crude measures of the quality of the uterine environment. In addition, the effects of childhood health and economic circumstances may only become apparent in middle adulthood. Low socioeconomic status in childhood might trigger poor health behaviors that take time to affect health adversely. Some childhood health conditions may not produce deterioration in health until middle age.

An alternative to these hypotheses - which is also consistent with the reduced-form evidence that child circumstances have a lasting impact - is that childhood circumstances affect adult outcomes through their effects on educational attainment, health, and social status early in adulthood. Under this alternative, $\beta_{\mathrm{C}}$ and $\alpha_{\mathrm{C}}$ will be zero. The idea that childhood socioeconomic position affects health in middle adulthood through its effects on economic status in early adulthood has been supported by research conducted using the Whitehall data. The use of the NCDS allows us to examine this issue using a richer set of measures of childhood socioeconomic circumstances and childhood health outcomes.

Estimates of (1) and (2) also provide information on the dynamic relationship between economic status and health in young and middle adulthood. The cross effects of socioeconomic status on future health $\left(\alpha_{\mathrm{e}}\right)$ and of health on future economic status $\left(\beta_{\mathrm{h}}\right)$ are of particular interest. The large literature on the "gradient" - the positive association between health and economic status - contains a variety of hypotheses on how economic status affects health, and vice versa, with little consensus on which hypothesis is correct. Pathways models stress the idea that status in young adulthood influences future health (i.e. $\alpha_{\mathrm{e}}$ nonzero), largely through the effects of low economic status on psychosocial stress (Marmot et 
al., 1991). This literature argues that childhood circumstance and health in early adulthood are generally not as qualitatively important as adult socioeconomic status in determining adult health (i.e. that $\alpha_{\mathrm{h}}$ and $\alpha_{\mathrm{C}}$ are relatively less important than $\alpha_{\mathrm{e}}$ ). Brunner et al. (1999) state that "whatever the salient features of the adult socioeconomic environment may be, it seems they are equally or more important than circumstances in childhood" in determining cardiovascular risk among British civil servants (p. 762).

The hypothesis that $\beta_{\mathrm{h}}$ is non-zero - that health affects future social status-is often referred to in the epidemiological literature as the "health selection" or the "social drift hypothesis" (Adler et al., 1994). The literature on pathways models argues that although some early health problems - in particular severe forms of mental illness such as schizophrenia or major depression - may affect future socioeconomic status, there is little evidence that current health affects future economic status (Chandola et al., 2003). However, this view is contradicted by other evidence that indicates that poor health in adulthood may indeed lower economic status and, specifically, earnings, through reduced labor supply and lower labor market productivity (Smith, 1999, 2003; Case and Deaton, 2003; Wu, 2003). ${ }^{16}$ This evidence is consistent with a model in which health is a form of human capital. Poor health may have a direct effect on labor market productivity, reducing wage rates at every age. If, in addition, poor health reduces the rate at which workers accumulate skills, then poor health would also slow the rate of wage growth over time. Health may also affect labor supply, and earnings - the product of the wage rate and hours worked - will be reduced if those in poorer health work fewer hours. Those in poorer health may have more spells out of the labor force or may choose to leave the labor force altogether, and time spent out of the labor force may also reduce wage growth by reducing the amount of accumulated labor market experience. These links from health to socioeconomic status should result in non-zero values of $\beta_{\mathrm{h}}$ (positive if higher values of $h$ represent better health, and negative if the reverse.)

We use estimates of (1) and (2) to examine which implications of these models find support in our data. Before turning to the estimates, two econometric issues require discussion. First, the parameter estimates of (1) and (2) will be unbiased only under mean independence between the errors terms and $e_{\mathrm{Y}}, h_{\mathrm{Y}}, \boldsymbol{C}$, and $S$, i.e. $E\left[\varepsilon_{\mathrm{M}}^{\mathrm{e}} \mid e_{\mathrm{Y}}, h_{\mathrm{Y}}, \boldsymbol{C}, S\right]=0$ and $E\left[\varepsilon_{\mathrm{M}}^{\mathrm{h}} \mid e_{\mathrm{Y}}, h_{\mathrm{Y}}, \boldsymbol{C}, S\right]=0$. There are situations under which conditional mean independence may not hold. There may be individual heterogeneity that is not measured by $\boldsymbol{C}$-for example, individuals may have unobserved personality traits or genetic characteristics that result in both poor health and low socioeconomic status throughout the life span. The idea that unobserved heterogeneity can lead to spurious state dependence in models with lags is well understood (Heckman, 1981). Unfortunately, solutions to this problem either require a set of valid instruments for status and health at younger ages, or the use of fixed effects approaches that require long panels of data. In our case, no plausible instruments are available. Furthermore, the panel is not long enough to estimate equations with individual fixed effects, nor is it obvious that fixed effects models, which rely on the assumption that coefficients are constant over time, make sense when looking at health and social status

\footnotetext{
16 Adams et al. (2003) concludes that some types of adverse health events result in reductions in wealth. However, because this paper relies on a sample of elderly individuals, there is only limited scope for health to affect economic status through reduced earnings and work hours.
} 
over a period of several decades. In what follows, we include a large set of variables in $\boldsymbol{C}$, and assume that this set of variables is rich enough to capture all individual heterogeneity. Indeed, our ability to control for a large set of childhood characteristics is an advantage over much of the previous literature that examines health and SES dynamics.

A second issue is that our estimates may reflect macro shocks-either economic or health shocks that affect large numbers of individuals in specific calendar years. To take an extreme example, an episode of infectious disease that happened to affect predominantly poor individuals in the year 2000, when the cohort was 42 year old, could result in a negative association between economic status at age 33 and health at age 42 when such a relationship does not generally exist. This is a generic problem when using cohort data that are not pooled across years. Although we know of no obvious macroeconomic or health shocks that could be driving our results, it will be useful in future work to estimate similar models using data on cohorts born at different dates.

\subsection{Results}

Table 6 presents estimates of (1) and (2) for men in the NCDS at 42. We restrict our attention to men, because less than half of women report working full-time at age 42 , and socioeconomic status is derived from occupation. We leave the question of whether a woman's health responds more to her own socioeconomic status — or that of her husband's - for future work. ${ }^{17}$

The first panel in Table 6 presents results from ordered probits of socioeconomic status at age 42 on childhood health and circumstance. Column 2 presents results from the reduced form analysis (column 5 of Table 5). Beyond the column 2, each column adds controls to the reduced form model. These are for completed education (column 3), education and SES in earlier adulthood (column 4), education and health in earlier adulthood (column 5) and education, SES and health in earlier adulthood (column 6). Health and social status in earlier adulthood are added as sets of indicator variables (for health $=$ good, fair, poor at ages 23 and 33; and for socioeconomic status = managerial, non-manual skilled, manual skilled, semiskilled, unskilled at ages 23 and 33). The table reports $p$-values from chi-square tests for the joint significance of family background (mother's education and SES, and father's education and SES); uterine environment (prenatal smoking, low birthweight); and childhood health (number of chronic conditions, height at age 16) for the 5439 men whose socioeconomic status was reported at age 42. Echoing the results presented in Table 5, we find that in the reduced form model, mother's and father's characteristics and childhood health measures are all significant correlates of adult socioeconomic status. Variables capturing the uterine environment, which contributed very little to the pseudo- $R^{2}$ in Table 5 , are not jointly significant predictors of adult SES.

Table 6 shows that the impact of mother's and father's education and social status is absorbed by the cohort member's socioeconomic status at ages 23 and 33 (parents' variables

\footnotetext{
17 The last columns of Table 1 presents summary statistics for this sub-sample, which show that their family backgrounds are similar to those for the sample as a whole. However, Table 1 also reveals that this sub-sample is slightly healthier in childhood and slightly better educated, on average, than is the sample as a whole. Parents' educations, family income at age 16, and self-rated health at 42 are identical for these groups.
} 


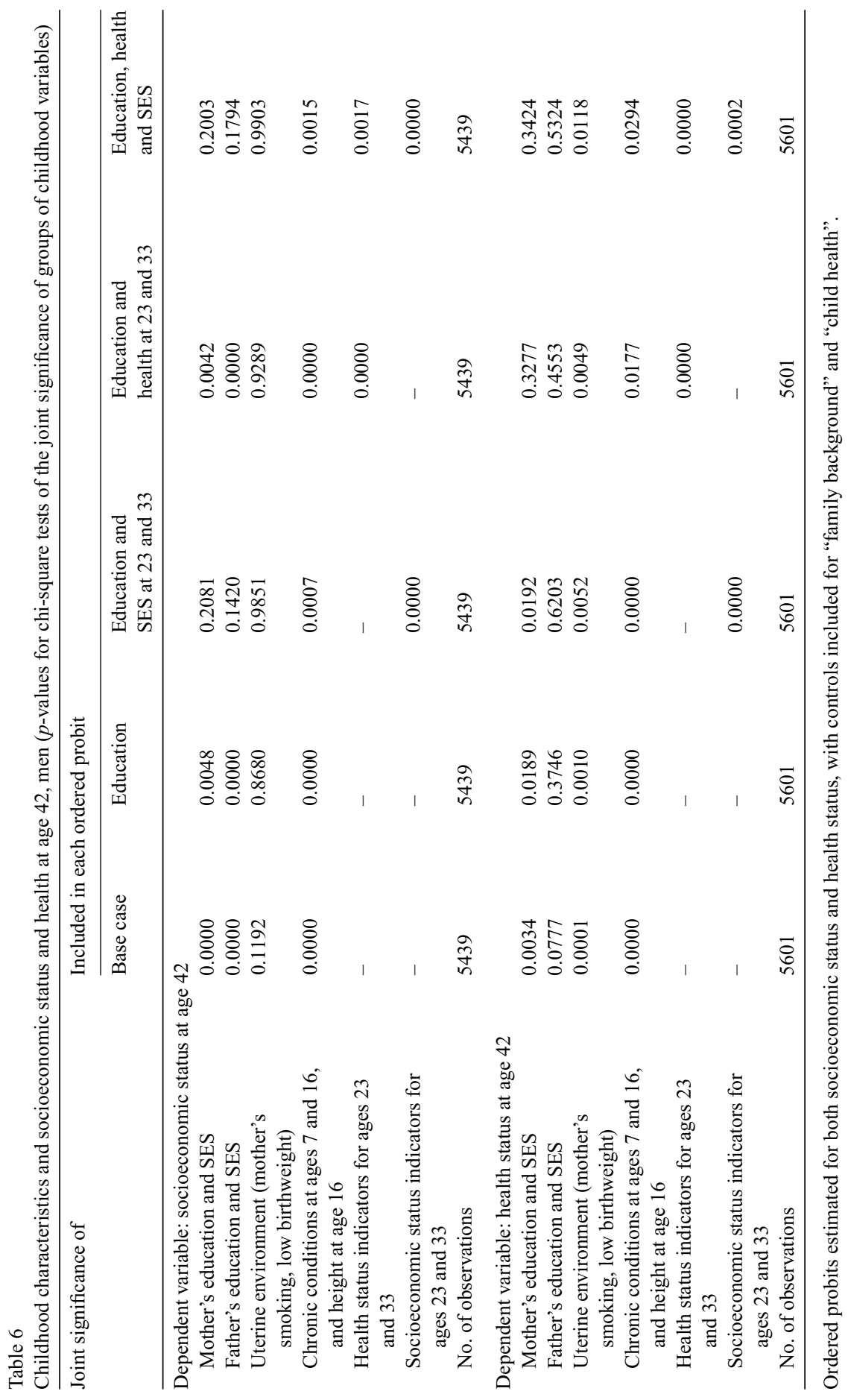



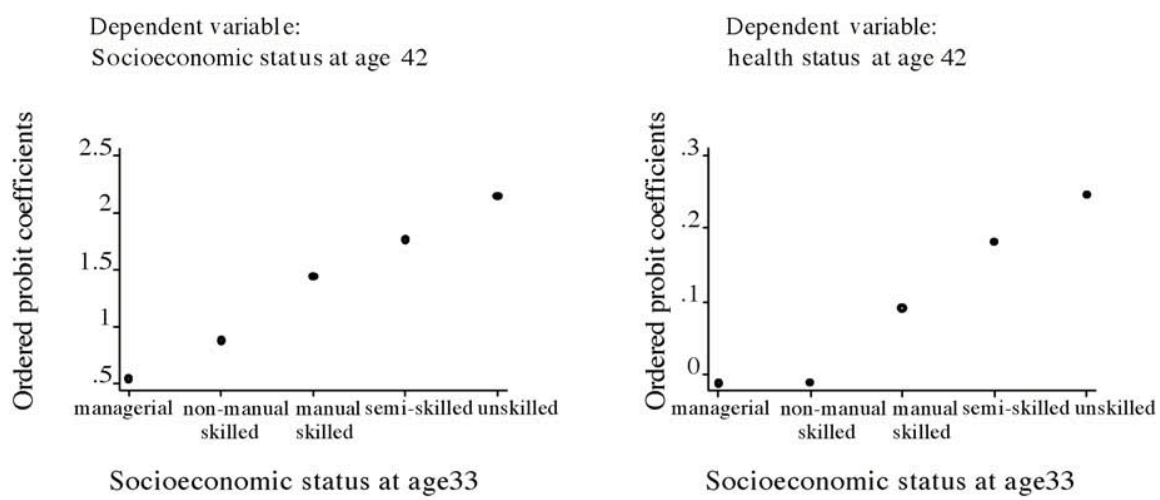

Fig. 4. The impact of socioeconomic status at age 33 on SES and health at age 42 .

remain significant when the cohort member's education is added, but become insignificant when indicators for the cohort member's SES at ages 23 and 33 are added to the ordered probit). It appears parents' educations and social status matter for their children's social status, and that this effect works through children's social status in early adulthood.

In contrast, chronic conditions in childhood and height at age 16 remain jointly significant predictors of social status at age 42 , even with controls for the cohort member's education, and his SES and health at ages 23 and 33. Childhood health appears to have a continuing effect on social status through middle age. Coefficient estimates from the ordered probit suggest that this effect is working through the number of chronic conditions the child experienced at age 16, with children's mental and emotional conditions at age 16 playing the largest role.

Both socioeconomic status and health in earlier adulthood are significant predictors of social status at age 42 . Worse health at age 33 is associated with lower socioeconomic status at age 42 . The effect of earlier socioeconomic status on current SES - corresponding to $\beta_{\mathrm{e}}$ in Eq. (1) - can be seen in the left panel of Fig. 4, which graphs coefficients on socioeconomic status at age 33 from an ordered probit of the determinants of SES at age 42, in which we control for SES and health status at age 33. Relative to having been a professional at age 33 (the omitted category), each category below this (managerial $=2$, skilled non-manual $=3$, skilled manual $=4$, semi-skilled $=5$, unskilled $=6$ ) is associated with a lower social status (higher number) at age 42 , with a monotonic increase from managerial through to unskilled worker.

The second panel of Table 6 presents a parallel analysis for health status at age 42 . Here, we find that mother's education and social status influence children's health in middle age through their effect on health in early adulthood. The $p$-value on mother's characteristics remains significant, even with controls for SES at ages 23 and 33. Upon the inclusion of health status at ages 23 and 33, mother's education and SES variables become jointly insignificant. Father's education and SES influence son's adult health through a different route. Father's characteristics become jointly insignificant when we control for cohort member's educational attainment, suggesting that fathers influence their sons' educational attainment, which in turn affects their health in adulthood. 
That the uterine environment has a lasting effect on health status can be seen by looking at the third row of the panel. With controls for education, health at 23 and 33, and social status at 23 and 33 , we find the variables for uterine environment remain jointly significant predictors of health at age 42. The coefficients from the ordered probits underlying Table 6 suggest that indicators that mother's prenatal smoking was heavy or variable are the most important variables in this set.

We also find that childhood chronic conditions continue to play a role in health in middle age. As was true for SES at age 42, the most important predictor in this set is the number of chronic conditions reported for the child at age 16 . When conditions are broken into categories-physical impairments; mental and emotional conditions; and systems conditionswe find that all three contribute equally to poorer health observed at age 42 .

Health at age 23 and 33 are significant predictors of health at age 42 , as are indicators of socioeconomic status at these ages. The relationship between SES at age 33 and health status at age 42 - corresponding to $\alpha_{\mathrm{e}}$ in Eq. (2) — can be seen in the right panel of Fig. 4, which presents coefficients from an ordered probit of health status at 42 on SES and health at age 33 . We find that, relative to being a professional, managers and non-manual skilled workers suffer no health penalty between ages 33 and 42: for both of these groups, the coefficients are small and insignificantly different from zero. However, for manual workers, we find deterioration in health status between ages 33 and 42 , with the deterioration greatest for unskilled workers. These results suggest that it may be manual work, rather than psychosocial stress associated with being a worker of a lower class, that is responsible for the effect of social status on health later in middle age.

Overall, the results in Table 6 present evidence that parents' educations and socioeconomic status influence health and socioeconomic status in middle age largely through their impact on health and economic status in early adulthood. In contrast, chronic conditions in childhood - particularly those observed at age 16 - and prenatal environment appear to have a direct effect on health in adulthood, even when controls are added for educational attainment, health and economic status in younger adulthood.

\section{Conclusions}

Our evidence suggests a potentially important role for all three models introduced earlier. Consistent with life-course models of health, childhood health conditions have a lasting impact on health and socioeconomic status in middle adulthood. Consistent with the fetal origins hypothesis, the uterine environment appears to play a significant role as a health determinant in middle age. The impact of the uterine environment is not reduced by controls for childhood health, educational attainment, health in early adulthood, or socioeconomic status.

Our results also provide some support for pathways models, in that we find childhood factors affect initial adult social position, which in turn affects health in middle age. However, the impact of social status in early adulthood on health in middle age appears to work through the increased probability of being a manual laborer: managerial workers and skilled nonmanual workers do not face higher risks of poorer health at age 42 . 


\section{Acknowledgement}

We thank Angus Deaton and Jeff Kling for useful discussions, and Janet Currie, Helen Levy, seminar participants at several universities and an anonymous referee for useful comments. This research has been funded in part through NIH grant R01 HD4114101(National Institute for Child Health and Development). Fertig acknowledges support from a MacArthur Foundation postdoctoral fellowship while writing this paper.

\section{References}

Adams, P., Hurd, M.D., McFadden, D., Merrill, A., Ribeiro, T., 2003. Healthy, wealthy and wise? Tests for direct causal paths between health and socioeconomic status. Journal of Econometrics 112 (1), 3-56.

Adler, N.E., Boyce, T., Chesney, M.A., Cohen, S., Folkman, S., Kahn, R.L., Syme, S.L., 1994. Socioeconomic status and health: the challenge of the gradient. American Psychologist, 15-24.

Barker, D.J.P., 1995. Fetal origins of coronary heart disease. British Medical Journal 311 (6998), 171-174.

Brunner, E., Blane, S., Smith, D., Marmot, D., 1999. When does cardiovascular risk start? Past and present socioeconomic circumstances and risk factors in adulthood. Journal of Epidemiology and Community Health $53,757-764$.

Case, A., Deaton, A., 2003. Broken down by work and sex: how our health declines. NBER Working Paper 9821, December 2003.

Case, A., Lubotsky, D., Paxson, C., 2002. Socioeconomic status and health in childhood: the origins of the gradient. American Economic Review 92 (5), 1308-1334.

Case, A., Paxson, C., 2001. Mothers and others: who invests in children's health? Journal of Health Economics 20, 301-328.

Case, A., Paxson, C., 2004. Sex differences in morbidity and mortality. Center for Health and Wellbeing Discussion Paper, Princeton University, http://www.wws.princeton.edu/chw/research/papers.php, forthcoming Demography.

Chandola, T., Bartley, M., Sacker, A., Jenkinson, C., Marmot, M., 2003. Health selection in the Whitehall II study, UK. Social Science and Medicine 56 (10), 2059-2072.

Currie, J., Hyson, R., 1999. Is the impact of health shocks cushioned by socio-economic status? The case of low birthweight. American Economic Review Papers and Proceedings 89 (2), 245-250.

Currie, J., Madrian, B., 1999. Health, health insurance and the labor market. In: Ashenfelter, O., Card, D. (Eds.), Handbook of Labor Economics. North Holland, Amsterdam, pp. 3309-3407 (Chapter 50).

Currie, J., Stabile, M., 2004. Socioeconomic status and health: why is the relationship stronger for older children? American Economic Review 93 (5), 1813-1823.

Gertler, P.J., Boyce, S., 2001. An experiment in incentive-based welfare: the impact of PROGRESA on health in Mexico. Mimeo, 3 April 2001, University of California, Berkeley.

Gregg, P., Machin, S., 1998. Child development and success or failure in the youth labour market. Centre for Economic Performance Discussion Paper 397, London School of Economics and Political Science.

Heckman, J., 1981. Statistical models for discrete panel data. In: Manski, C.F., McFadden, D.L. (Eds.), Structural Analysis of Discrete Data and Econometric Applications. The MIT Press, Cambridge (Chapter 3).

Idler, E.L., Kasl, S.V., 1995. Self-ratings of health: do they also predict change in functional ability? Journal of Gerontology: Social Sciences 508 (6), S344-S353.

Institute of Medicine (IOM), 2001. Clearing the Smoke: Assessing the Science Base for Tobacco Harm Reduction. National Academy Press, Washington.

Kuh, D.J., Wadsworth, M.E., 1993. Physical health status at 36 years in a British national birth cohort. Social Science and Medicine 37 (7), 905-916.

Marmot, M.G., Shipley, M.J., Rose, G., 1984. Inequalities in death—specific explanations of a general pattern. The Lancet 1 (8384), 1003-1006. 
Marmot, M.G., Smith, G.D., Stansfeld, S., Patel, C., North, F., Head, J., White, I., Brunner, E., Feeney, A., 1991. Health inequalities among British civil servants: the Whitehall II study. The Lancet 337, 1387-1393.

Marmot, M., Brunner, S., Hemingway, S., 2001. Relative contributions of early life and adult socioeconomic factors to adult morbidity in the Whitehall II study. Journal of Epidemiology and Community Health 55, 301-307.

Ozanne, S.E., Hales, C.N., 2004. Catch-up growth and obesity in male mice. Nature 427, 411-412.

Ravelli, A.C.J., van der Meulen, J.H.P., Michels, R.P.J., Osmond, C., Barker, D.J.P., Hales, C.N., Bleker, O.P., 1998. Glucose tolerance in adults after prenatal exposure to famine. The Lancet 351, 173-177.

Reville, R.T., 1995. Intertemporal and life cycle variation in measured intergenerational earnings mobility. Mimeo, RAND, Santa Monica, CA.

Slotkin, T.A., 1998. Fetal nicotine or cocaine exposure: which one is worse? The Journal of Pharmacology and Experimental Therapeutics 285 (3), 931-945.

Smith, J.P., 1999. Healthy bodies and thick wallets: the dual relationship between health and economic status. Journal of Economic Perspectives 13 (2), 145-166.

Smith, J.P., 2003. Consequences and predictors of new health events. NBER Working Paper W10063.

Thomas, D., Frankenberg, E., Friedman, J., Habicht, J.-P., Hakimi, M., Jaswadi, Jones, N., Pelto, G., Sikoki, B., Seeman, T., Smith, J.P., Sumantri, C., Suriastini, W., Wilopo, S., 2003. Iron deficiency and the well-being of older adults: early results from a randomized nutrition intervention. Mimeo, May 2003, University of California, Los Angeles.

$\mathrm{Wu}, \mathrm{S} ., 2003$. The effects of health events on the economic status of married couples. Journal of Human Resources $36(1), 209-230$. 